\title{
Design and Implementation of Appliance Controller using Traditional or Smart Phone
}

\author{
Hussein Abdul Razzaq Lafta \\ University of Baghdad \\ College of Engineering \\ Computer Engineering Department
}

\begin{abstract}
Mobile phones are widely used nowadays, for different application such as wireless control and monitoring due to its availability and ease of use. The implemented system is based on "global system mobile (GSM)" network by using "short message service (SMS)". The design mainly contains a GSM modem and interfacing unit circuit with microcontrollers.

This system could control up to eight different electrical devices such as light, Air conditioner, washing machine and many more applications which needed in daily life in different area (House, Office, or factory, etc.). The control is done by sending a specific SMS messages from traditional or smart phone. The controlling devices are restricted to a pre-defined phone number and are set in the software of the receiver. Also feedback status of eight devices can be requested in designed system.
\end{abstract}

The designed receiver recovers syntax errors, like additional spaces, special symbols, and repeated letters.

\section{Keywords}

SMS, GSM modem, PIC Microcontroller, appliance controller, smart phone.

\section{INTRODUCTION}

Mobile phones are widely used nowadays, for different applications such as wireless control and monitoring, because of its availability and easy to use.

There are many definitions of GSM based appliance controlling available in the literature. Fadhil T. Aula, (2005) [1], presented a system of the PC remote Controlling with the Mobile Telephone through accessing the main PC ports; serial and parallel. Serial port for transferring data from Mobile phone to PC and parallel port for interfacing PC with real time controlling hardware. The system was implemented by using the SMS. Mohd Helmy Abd Wahab, et. al., (2010) [2], presented a GSM Based Electrical Control System for Smart Home Application. In this paper, a GSM module was used for receiving SMS from user's mobile phone that automatically enable the controller to take any further action. The system was integrated with microcontroller and GSM network interface. It reads message from the mobile phone and responds to control the devices according to the received message. Amit Chauhan, et. al., (2011) [3], proposed approach for designing remote control based on GSM mobile technology, and using SMS message that is generated by mobile user. It is implemented based on microcontroller that receives SMS and commands from a cellular phone over the GSM network. The microcontroller then carry outs the issued commands and then communicate the status of a given appliance or device back to the cellular phone. And C. K. Das, et. al., [4], proposed a method which enables users to control their home appliances and systems from anywhere using a cell phone. To access the control unit, the user should send an authentication code (DTMF) along with the required/desired function/action to his/her home control system via Global System for Mobile communication (GSM).

All surveyed researches do not work on smart phone applications, so, a system controlled by smart phone and also by a traditional phone will be a promising idea and remotely give on-off status function for all devices. The system is designed for controlling eight electrical devices by using SMS; any device switching was achieved by relays as shown in Figure 1. The paper organization is as follows, section two contains the design and implementation of the system. The results were shown in section three, finally the discussion and conclusions could be found in section four.

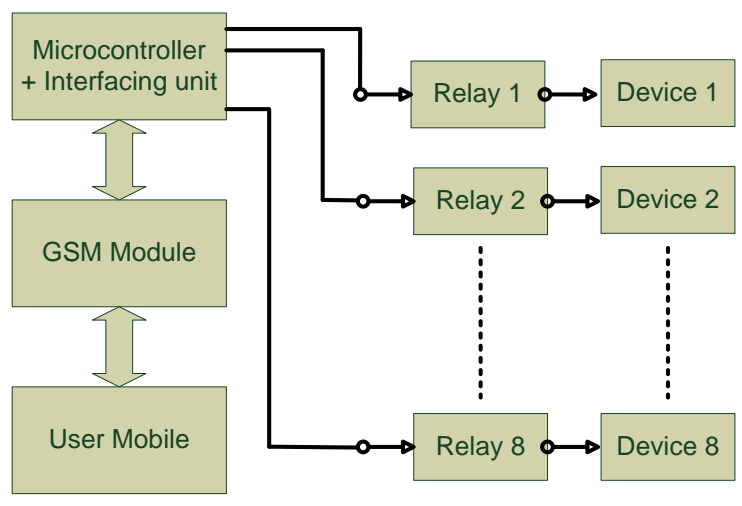

Fig 1: Block diagram of the appliance controller system

\section{DESIGN AND IMPLEMENTATION}

\subsection{The Transmitter}

A system is designed to transmit a text SMS message to control the appliances to make ON or OFF state for a in a certain places. Furthermore, the system could reads or checks the status of the eight electrical devices which are under the system control. This text message could be transmitted by one of two schemes:-

\section{Using traditional phone}

In this scheme an SMS message is sent from the traditional cell phone to the GSM modem using one of the following cases by sending syntax as following:

Case A- 1ON 2OFF 3OFF 4ON 5ON 6OFF 7ON 8OFF

Case B- 3OFF

Case C- ALL ON 


\section{Case D- ALL OFF}

Case E- Status

Notice that cases (A, B, C, and D) are used to appliance's control according to the information that is embedded in transmitted SMS message, while In case E, the system could checks the status of the eight appliances by sending a status SMS message and receiving a status feedback message which contains the state of the all eight appliances.

\section{- Using smart phone}

Since the wide spread the smart phones and its applications, also for making SMS messages easier and faster we had developed Android-based smart phone application, to do all cases (A, B, C, D, and E) that explained in traditional phone.

The screenshot captured in Android-based smart phone device for the appliance controller application is shown in Figure 2. The application alters the ON-OFF status of Android switches according to the received feedback SMS message. The flowchart of the sending SMS message is shown in Figure 3a while flowchart of the sending status SMS message and receive feedback SMS message is shown in Figure $3 b$.

GUARD TIME:- The time required for the status request and feedback SMS messages (the worst case)

Condition: Is correct phone NO. and (the difference between time of the status SMS message and time of last received SMS message is less than GUARD TIME), To ensure that the application is not used an old message in case of non-arrival of the feedback SMS message.

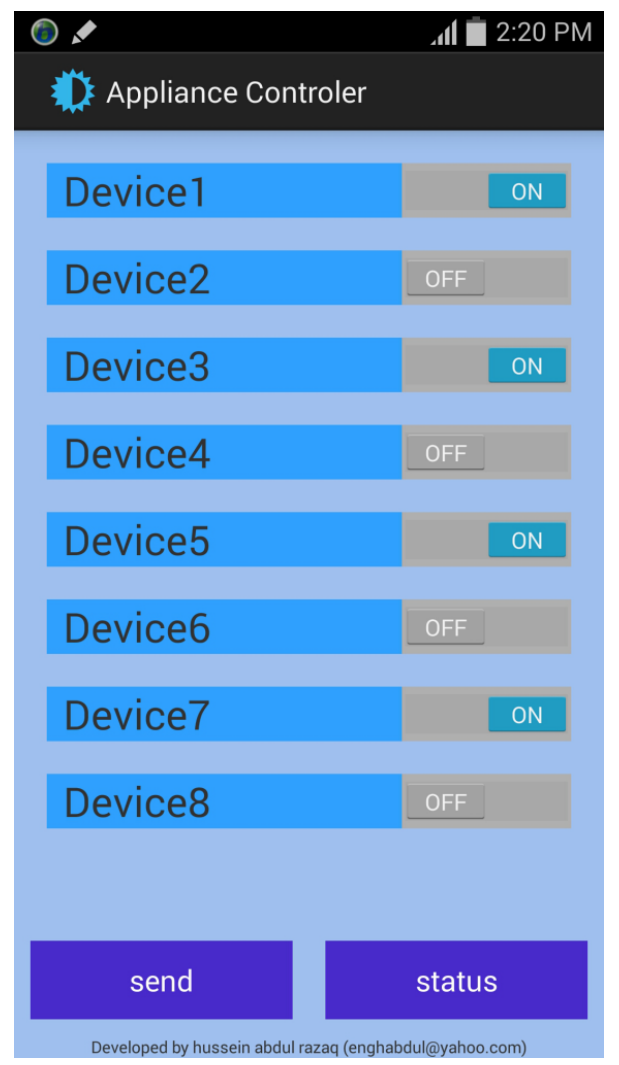

Fig 2: Screenshot captured in Android-based smart phone device

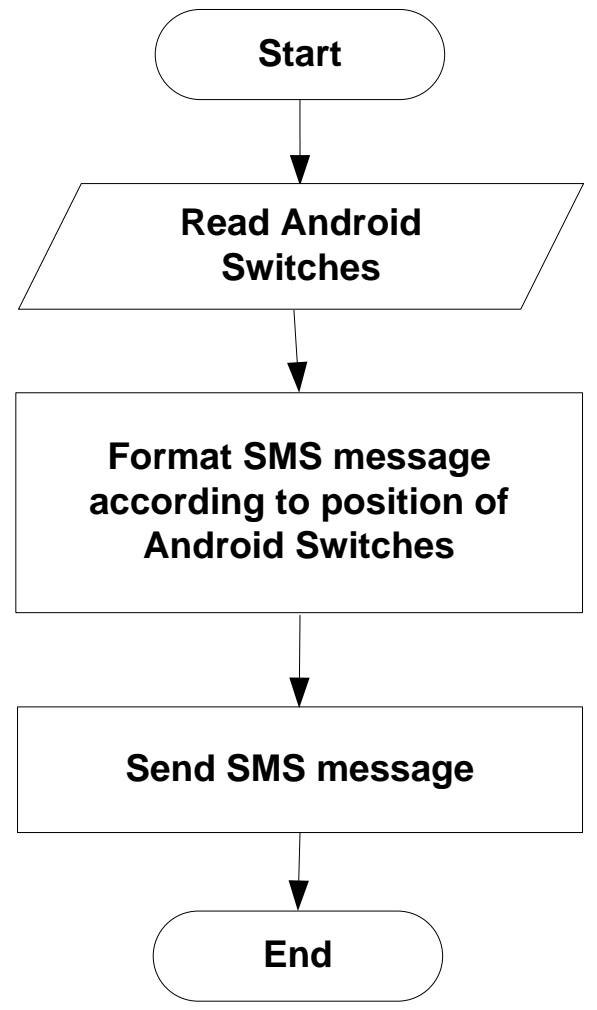

Fig 3a: Flowchart of the sending SMS message

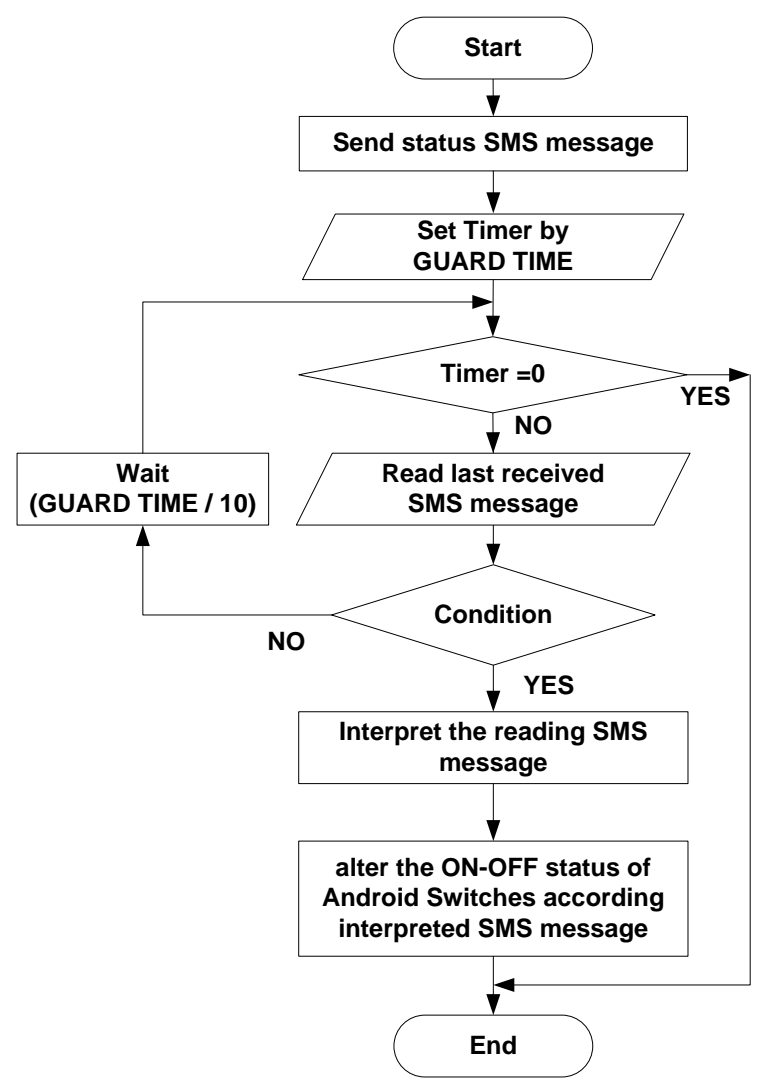

Fig 3b: Flowchart of the sending status SMS message and receive feedback SMS message 


\subsection{The Receiver Circuit}

The hardware of the receiver contains the two (PIC16F887) microcontrollers [5], GSM modem, and Interfacing unit circuit. The schematic circuit of the receiver is shown in Figure 4. The Vero board receiver circuit is shown in Figure 5 and the GSM modem (SIM300) [11] is shown in Figure 6.

\section{- Microcontrollers}

The first microcontroller is used to receive and read the SMS message from the GSM modem and interpret it, then interpreted message is used to control appliances (switch ON or OFF the eight devices), this microcontroller activates the relays which are connected to corresponding device through relay driver circuit. The Man/Auto function is commonly used in industry for controlling the driver through three tap selector switch (ON, OFF, or Auto position), it is essential for maintenance purposes, as shown in doted black box (driver and relay NO.1) in Figure 4.

The second microcontroller is used to construct a new message according to the status of eight appliances and send it to the user mobile that sent the request. The flowchart of the receiver software is shown in Figure 7.

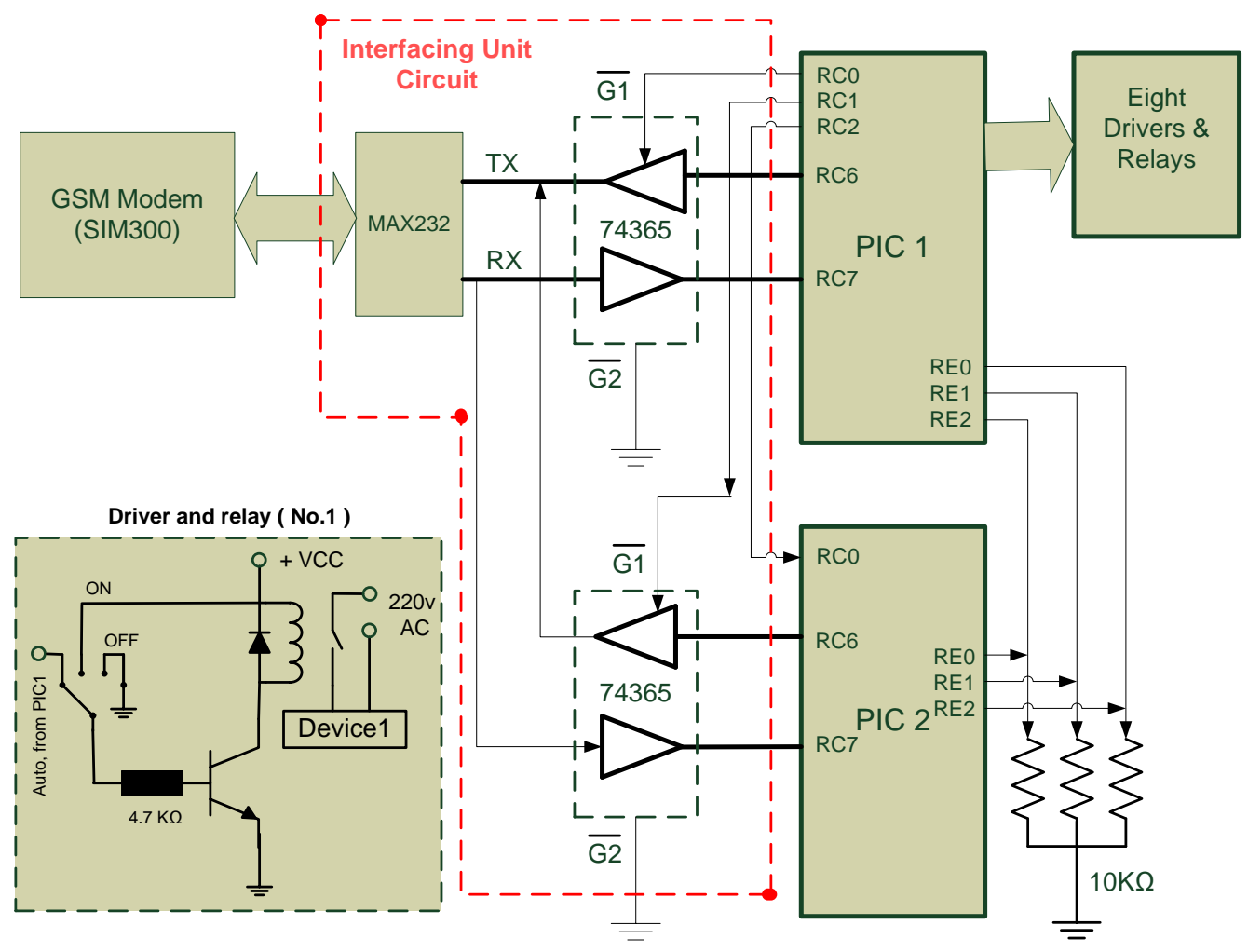

\section{- GSM Modem}

Modem encodes and decodes signals sent to and from the network servers. Modems are frequently associated with telephone systems, but wireless modems are used with computers and also with communication mediums. Wireless modem interfaces include PCMCIA, Compact Flash, USB and Serial Port. A GSM modem is a network device which connects to a GSM network. A GSM modem is a specialized type of modem which accepts a SIM card, and operates over a subscription to a mobile operator, just like a mobile phone, it can be used for sending and receiving SMS [6] [7].

In this project the GSM modem is interfaced through a Serial Port with a microcontroller IC. AT commands are used to

\section{cuit of the receiver}

automatically receive the SMS messages from the preconfigured number and system also sends the feedback SMS message to preconfigured number to tell us about the status of appliances [8].

\section{- Interfacing Unit Circuit}

Interfacing unit includes a MAX232 dual driver/receiver that includes a capacitive voltage generator to supply EIA-232 voltage levels from a single 5-V supply and a RS232 which is the most known serial port used in transmitting the data in communication and interface [9]. This unit is used to interconnect the PIC with the GSM modem. Also a three state buffer (74365) [10] is used for managing data transfer between microcontrollers with (MAX232). 


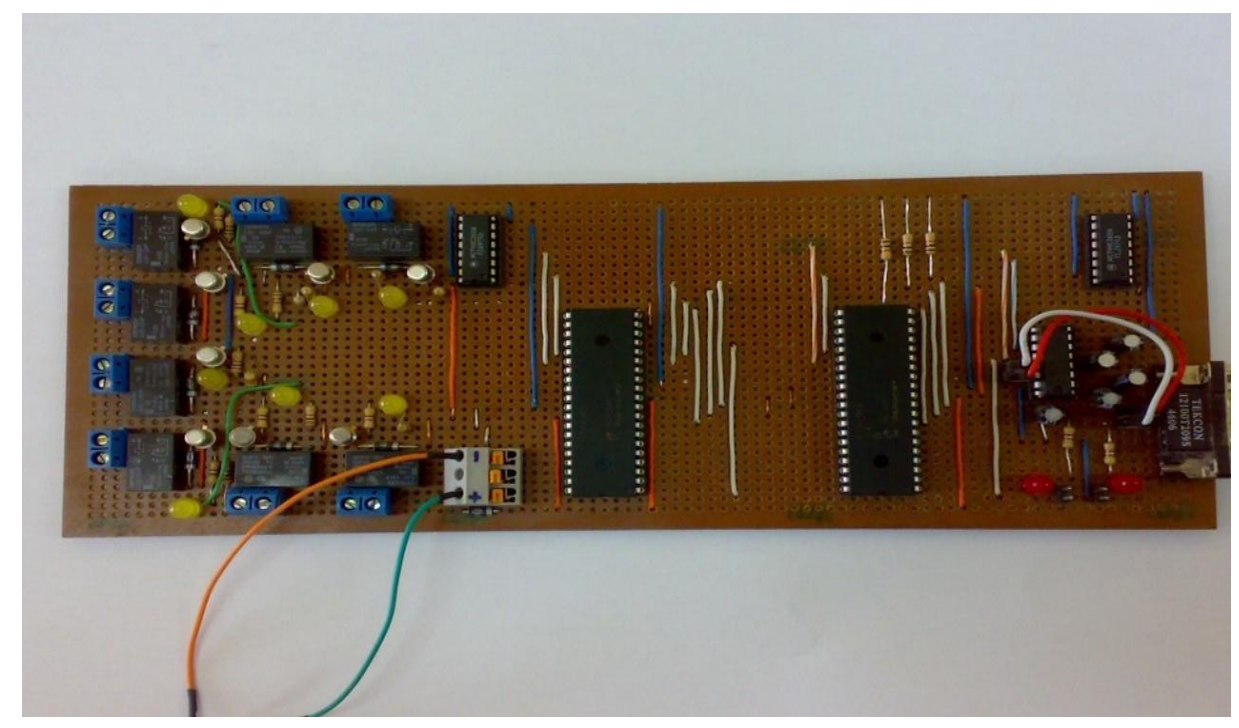

Fig 5: The Vero board receiver circuit

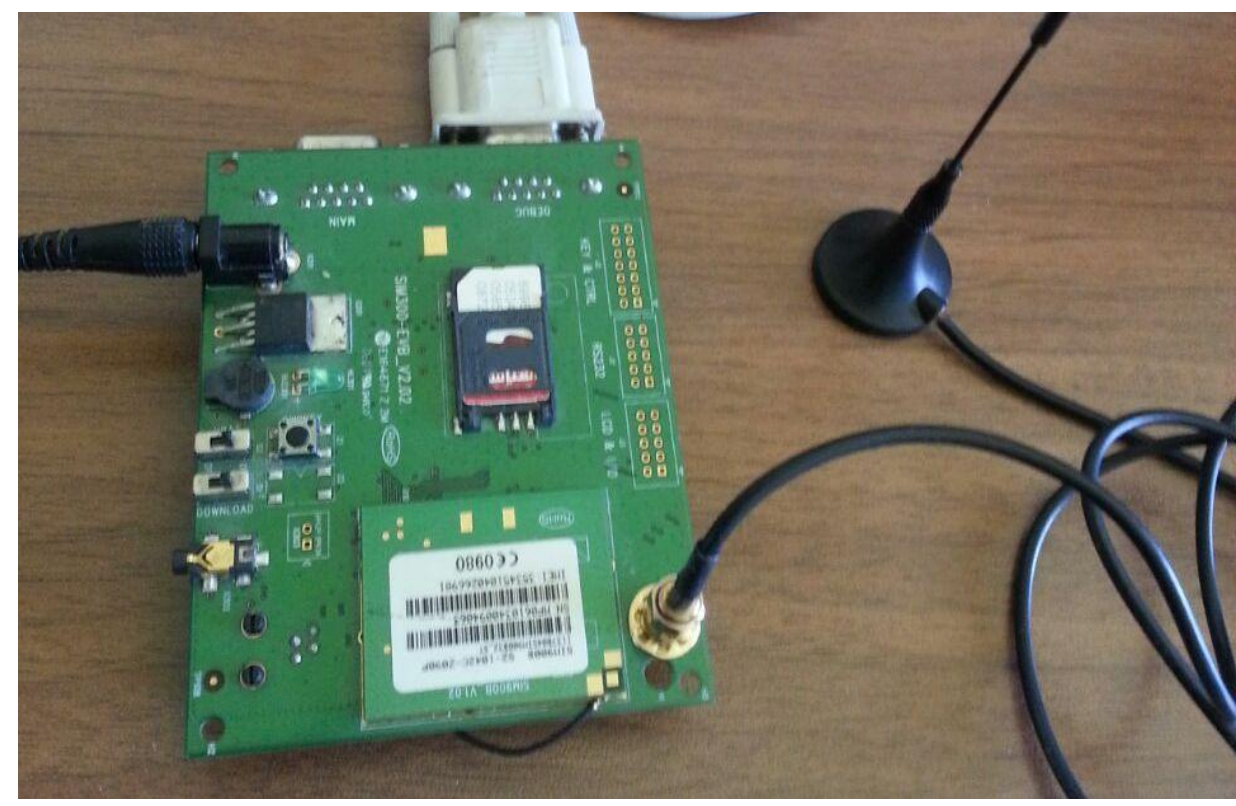

Fig 6: The GSM modem (SIM300) 


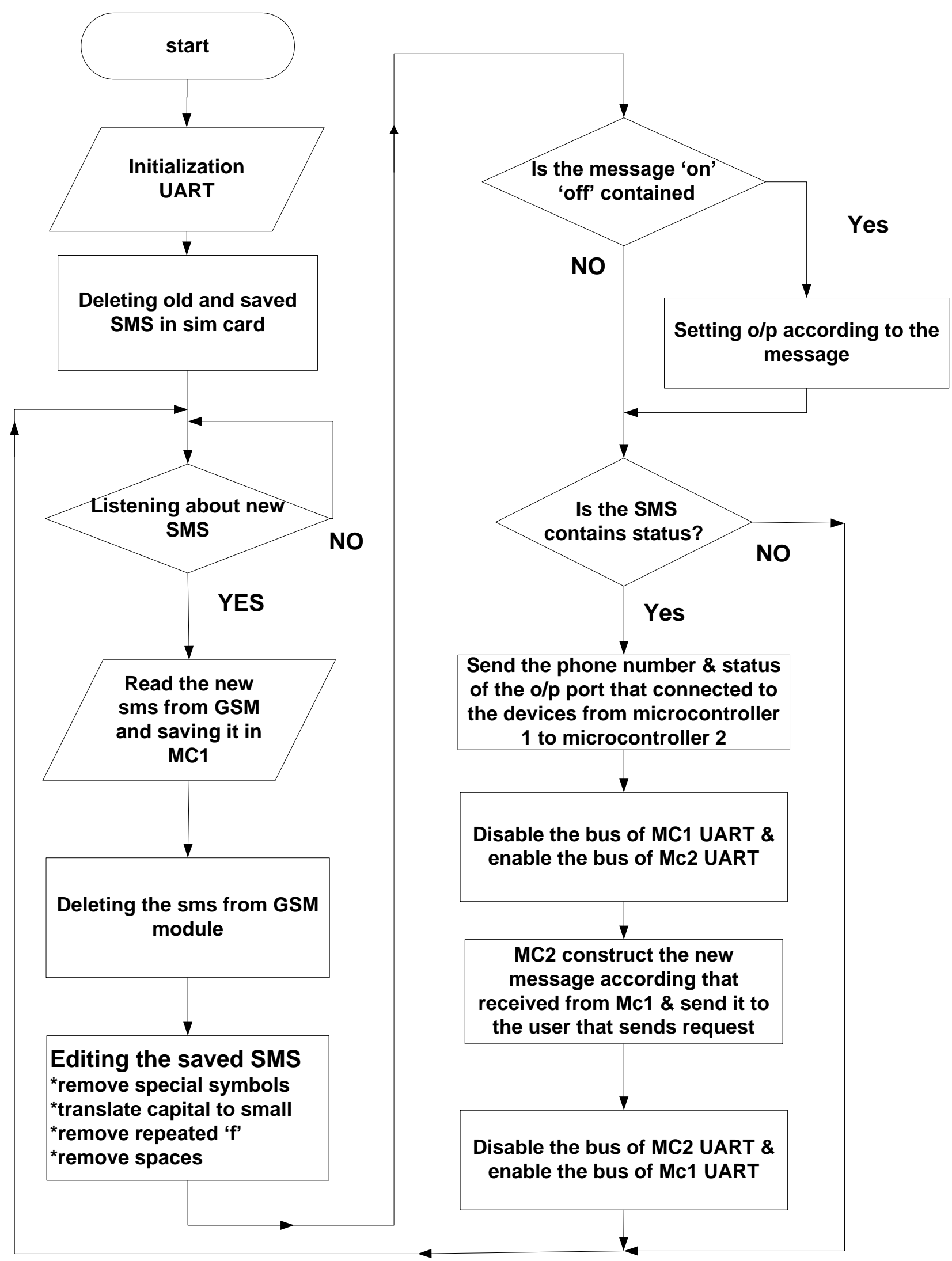

Fig 7: Flowchart of the software 


\section{RESULTS}

In the first case, it is selected to make all devices $\mathrm{ON}$ as shown in Figure 8.

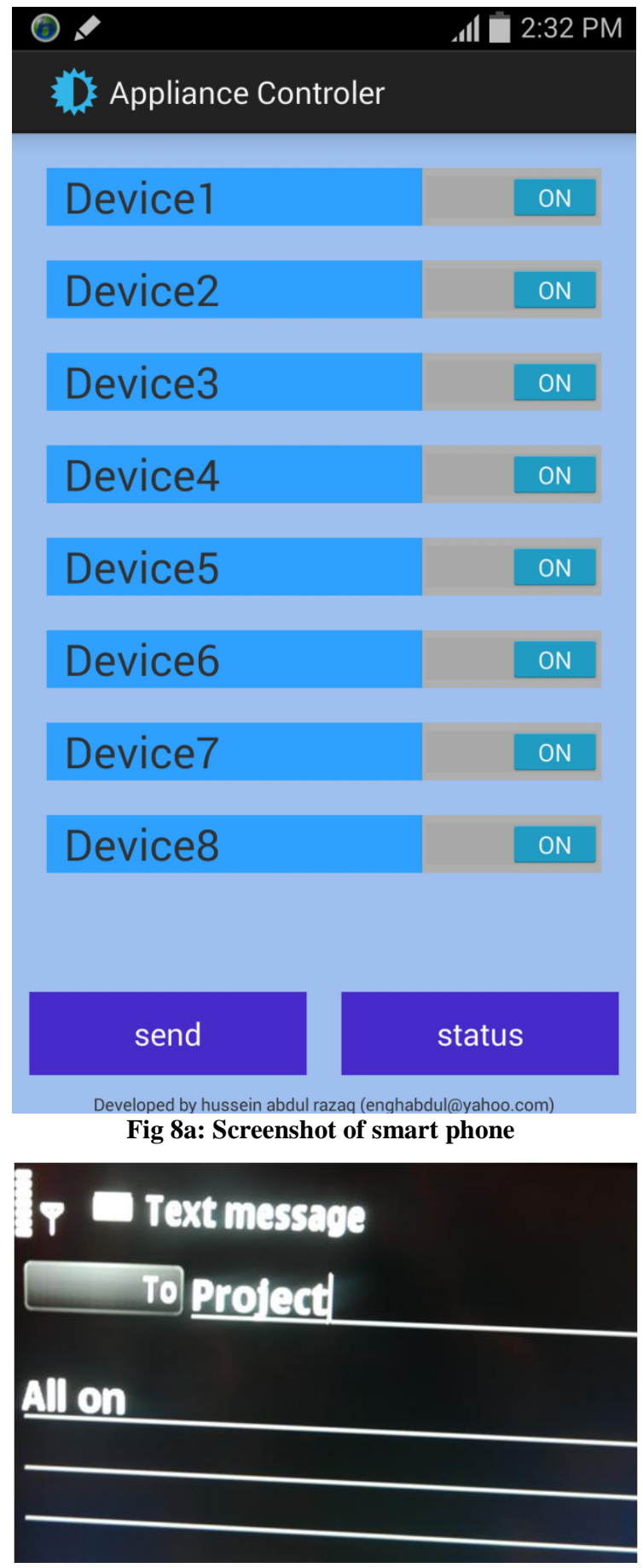

Fig 8b: The text message

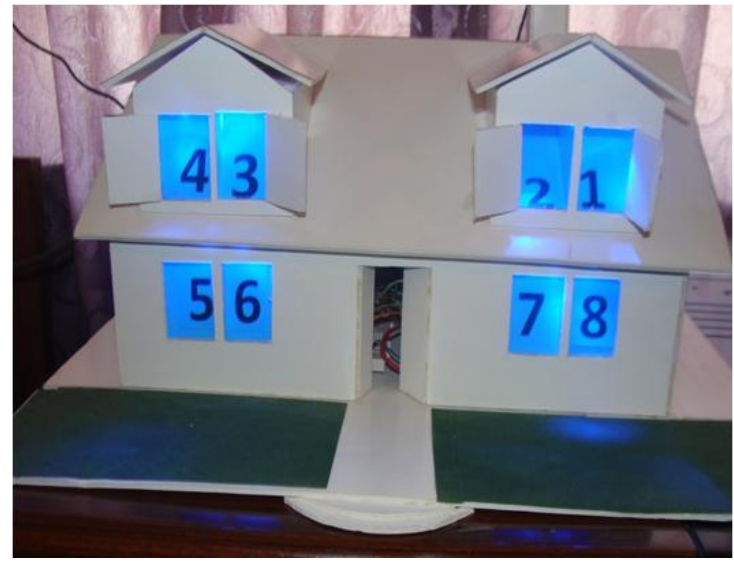

Fig 8c: The prototype of a home appliance

In the second case, it is selected to make the devices $(1,2,6$, and 8) ON, and others are OFF. This message contains some syntax errors such as single ' $\mathrm{f}$ ', convert the capital letters to small letters by adding the ASCI code of capital letters with 32 , and remove all the spaces and special symbols '=', '(', ')', and any other letters 'hello' as shown in Figure 9.

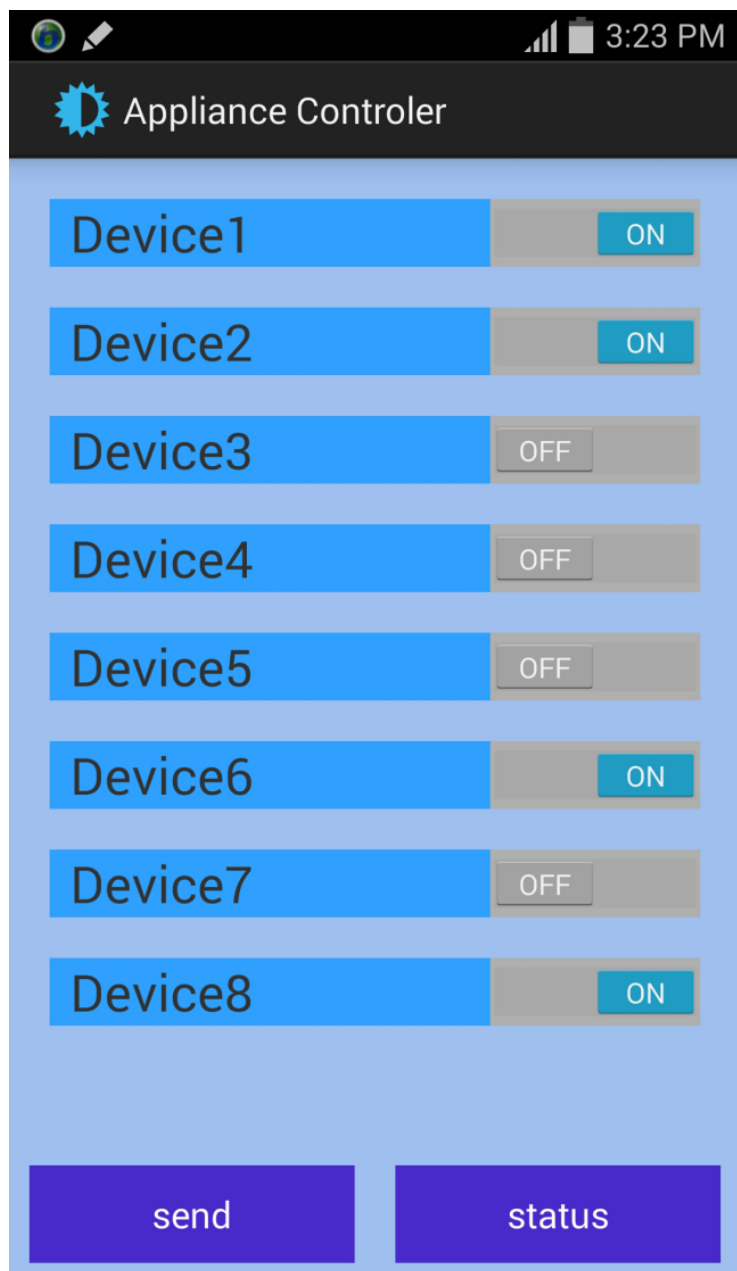

Developed by hussein abdul razaq (enghabdul@yahoo.com)

Fig 9a: Screenshot of smart phone 


\section{Q Text message}

To Project

\section{$3=0$ ff $4(\mathrm{OF}) 5$ of 7 o F F hello}

Fig 9b: The text message

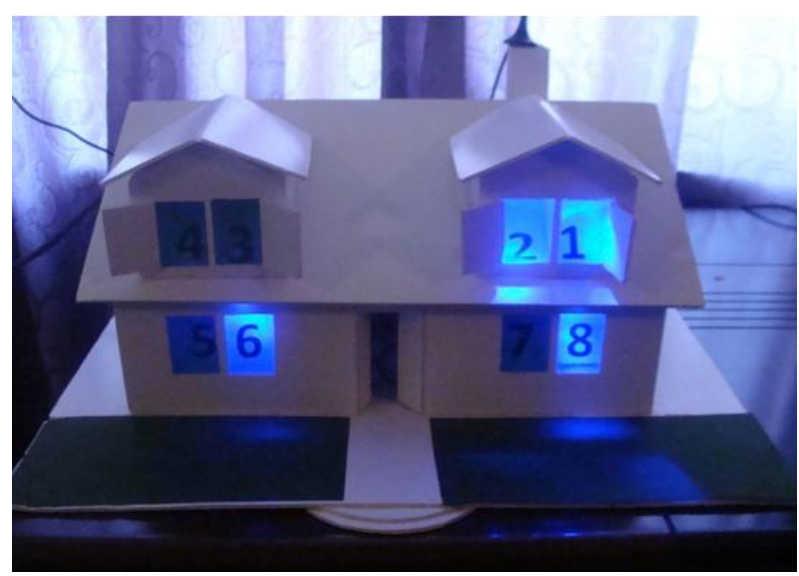

Fig 9c: The prototype of a home appliance

In the third case, it is selected to check the status of eight devices by sending SMS status message and receive another SMS feedback message that tell the states of the eight devices as shown in Figure 10.

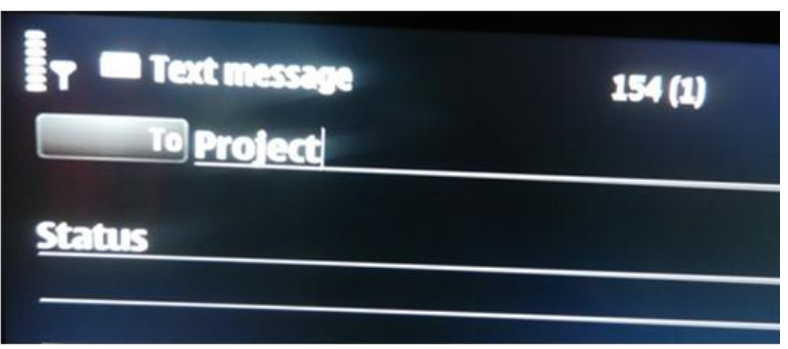

Figure10a: The text message

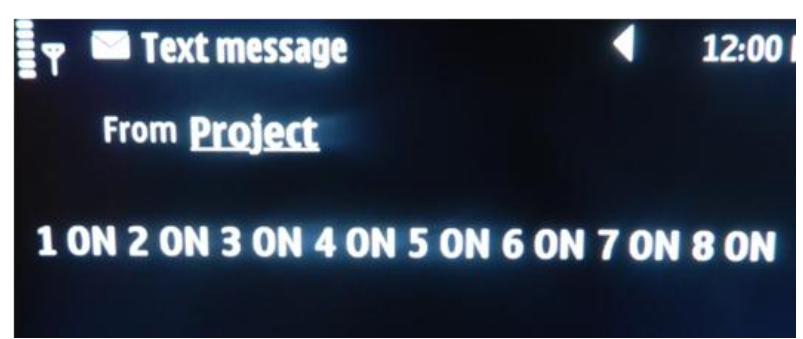

Fig 10b: The feedback text message

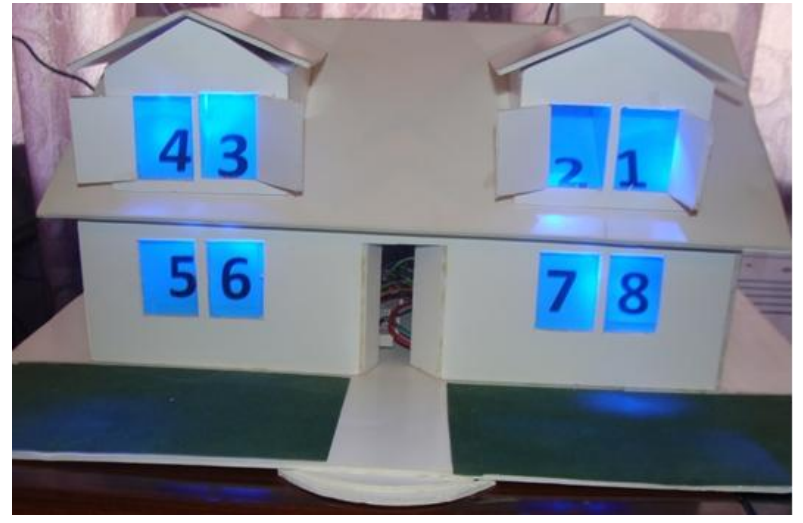

Fig 10c: The prototype of a home appliance

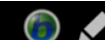

all 2:32 PM

Appliance Controler

\section{Device1}

Device2

Device3

\section{Device4}

\section{Device5}

\section{Device6}

\section{Device7}

\section{Device8}

\section{send}

status

Developed by hussein abdul razaq (enghabdul@yahoo.com)

Fig 10d: screenshot of smart phone 


\section{CONCLUSIONS}

Flexible controlled message using smart or traditional phone.

- The ability to check the status of controlled eight devices.

- Recovery from message's syntax errors, like additional spaces, special symbols, and repeated letters.

- SMS services provide an economical and convenient way to control the electrical devices, and are sometimes provided for free.

- Controlling any appliance remotely, and provides saving in time and in energy.

- Reliable, low power consumption, available components, and even PC are not needed.

\section{REFERENCES}

[1] Fadhil T. Aula, "Using SMS in Mobile Phone for Home Appliances Controlling Through PC Parallel Port Interfacing", University of Salahaddin, College of Eng., 2005.

[2] Mohd Helmy Abd Wahab, Norzilawati Abdullah, Ayob Johari, and Herdawatie Abdul Kadir , "GSM Based Electrical Control System for Smart Home Application". Journal of Convergence Information Technology, Volume 5, Number 1, February 2010

[3] Amit Chauhan, Reecha Ranjan Singh, Sangeeta Agrawal, Saurabh Kapoor, and S. Sharma, "SMS based remote control system". IJCSMS International Journal of Computer Science and Management Studies, Vol. 11, Issue 02, Aug 2011
[4] C. K. Das, M. Sanaullah, H. M. G. Sarower and M. M. Hassan, "Development of a cell phone based remote control system". International Journal of Electrical \& Computer Sciences IJECS Vol: 9 No: 10

[5] Microchip Technology - PIC 16F887 Data Sheet, Microchip2007:

http://ww1.microchip.com/downloads/en/DeviceDoc/412 91D.pdf

[6] GSM modem: http://www.nowsms.com/faq/what-is-agsm-modem

[7] Sadeque Reza Khan, Ahmed Al Mansur, Alvir Kabir, Shahid Jaman, and Nahian Chowdhury," Design and Implementation of Low Cost Home Security System using GSM Network". International Journal of Scientific \& Engineering Research Volume 3, Issue 3, March 2012

[8] AT command set: http://www.owen.ru/uploads/re_pm01_list_command.pdf

[9] MAX232, dual EIA-232 drivers/receivers: http://www.datasheetcatalog.org/datasheet/texasinstrume nts/max232.pdf

[10] Hex bus driver with 3-state output (74365): http://pdf.datasheetcatalog.com/datasheets2/69/699357_1 .pdf

[11] SIM300 Hardware description:http://www.datasheetpdf.com/datasheet/Simcom/647379/SIM300.pdf.html 